\title{
Novel Multilevel Hybrid Inverter Topology with Power Scalability
}

\author{
Emre Gurpinar, Alberto Castellazzi \\ Power Electronics, Machines and Control Group \\ University of Nottingham \\ Nottingham, UK \\ Email: emre.gurpinar@nottingham.ac.uk
}

\begin{abstract}
In this paper, a novel multilevel hybrid inverter is presented. The inverter is based on 2 floating capacitors and 16 active switches for five-level voltage waveform between the output of the inverter and neutral point of DC link. The proposed inverter structure, switching states and commutation scheme for different output voltage levels are presented. The proposed topology is simulated and verified experimentally. The simulation results show that proposed topology can achieve higher efficiency in comparison to state-of-the-art hybrid topologies due to reduced conduction and switching losses at low modulation index and light load conditions. Experimental results show that the converter is successfully operated up to $1 \mathrm{kV}$ DC link voltage and $12 \mathrm{~kW}$ output power.
\end{abstract}

Index Terms-Renewable energy, single-phase inverters, ANPC, active neutral point clamped inverter, stacked multicell converter, SMC, hybrid multilevel inverter

\section{INTRODUCTION}

Electricity generation from renewable energy sources such as wind, tidal, wave and solar has been one of the trending topics in power conversion research in order to reduce carbon emissions and dependency to limited fossil fuel supplies. Generating electricity by using photovoltaic panels and wind turbines has been one of the most studied topics. One of the main aims of the research in this area is increasing efficiency of the power electronics system that delivers the generated power from renewable sources to the grid.

Multilevel inverters have been discussed in literature as good candidates for high power conversion systems due to improved output voltage distortion, reduced voltage stress across power semiconductors and reduced filtering requirements [1], [2]. The first multilevel converter designs were based on neutral point clamped (NPC) and flying capacitor (FC) based topologies. These two approaches have been proposed for three and higher number of voltage levels. At high number of voltage levels (five and more), NPC based inverters suffer from high semiconductor count, high conduction losses and asymmetrical semiconductor switching loss. On the other hand, FC based topologies require complex control schemes for balancing flying capacitors and high energy storage in floating capacitors [1], [3].

Due to the limitations of NPC and FC based topologies for high number voltage levels (five and above), various hybrid topologies have been introduced [4]. One of the most popular hybrid topologies is five-level active neutral point clamped
(ANPC) inverter. ANPC is a member of half-bridge neutral point clamped inverter family and it was introduced in [5] as an alternative to three-level NPC inverter for improved loss balancing and better utilization of semiconductor chip areas in the inverter. Replacing diodes in NPC inverters with active switches provides additional zero states, and at the same time different modulation strategies can be applied with a flexible utilization of the redundant switching states. The three-level ANPC topology is extended to five-level ANPC (5L-ANPC) in [6]-[8] and presented in Fig. 1. 5L-ANPC is formed by 12 active switches and a floating capacitor $C_{f_{1}}$, where $C_{f_{1}}$ voltage is fixed to $\mathrm{E}$. By using the floating capacitor and neutral point, five voltage levels $(+2 \mathrm{E},+\mathrm{E}, 0,-\mathrm{E},-2 \mathrm{E})$ can be achieved between the output $(O U T)$ and neutral point $(N)$. Similar hybrid five-level topology based on two floating capacitors $C_{f_{1-2}}$ and 14 active switches has been introduced in literature [9]. The topology is presented in Fig. 2. The floating capacitor voltages are kept at one fourth of DC link voltage and the inductor $L_{f_{1}}$ is used for limiting inrush current between DC link capacitors and floating capacitors due to voltage variation across floating capacitors. Another hybrid multilevel inverter concept called "Stacked Multicell Converter" (SMC) is discussed in [10], [11]. The concept is based on increasing number of voltage levels at the output of the converter by introducing floating capacitor and active switch based cells. Five-level inverter based on SMC approach is presented in Fig. 3. In all three inverters presented in Fig. 1, 2 and 3, active devices are rated at one fourth of DC link voltage E.

In this paper, a new five-level hybrid inverter is presented. The details of the proposed topology including switching states and commutation scheme are presented in Section II. The simulation results including efficiency comparison with respect to 5L-ANPC is presented in Section III. Finally, the experimental results based on $12 \mathrm{~kW}$ prototype are presented in Section IV and discussed.

\section{Proposed InVERTer Topology}

The proposed five-level inverter topology in this paper is based on a hybrid configuration of neutral-point-clamp and floating capacitors. The topology is named as "Efficiency and Dense Architecture: EDA5" and filed for patent application [12]. The topology is formed by 16 active switches $S_{1}-S_{10}$, two floating capacitors $C_{f_{1-2}}$ and two DC-link capacitors 


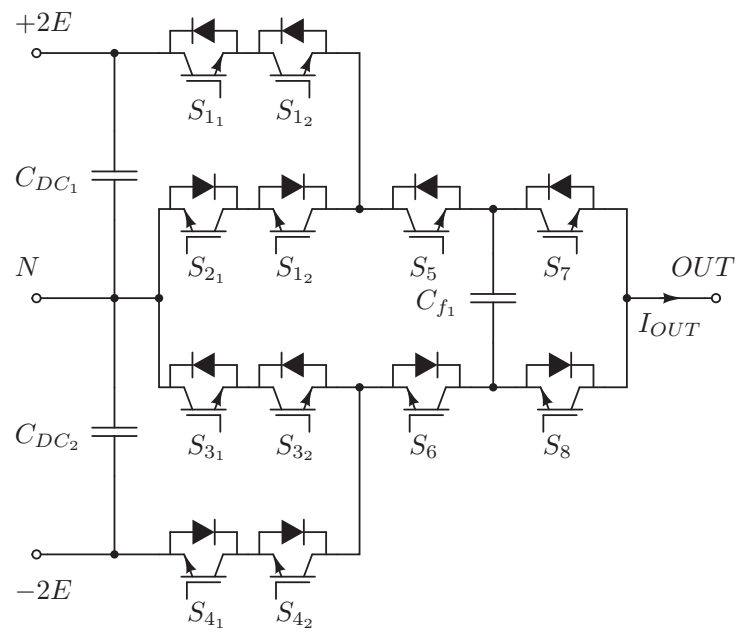

Fig. 1. 5L-ANPC inverter.

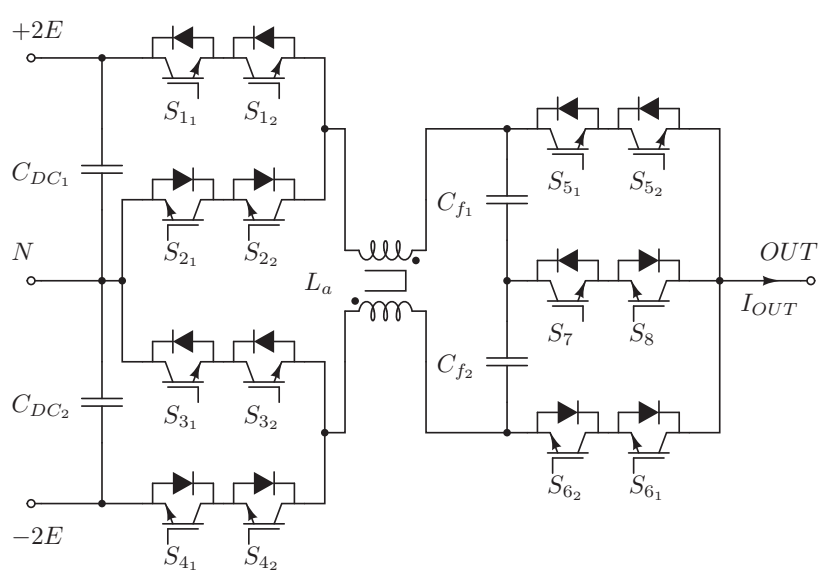

Fig. 2. FUJI five-level inverter.

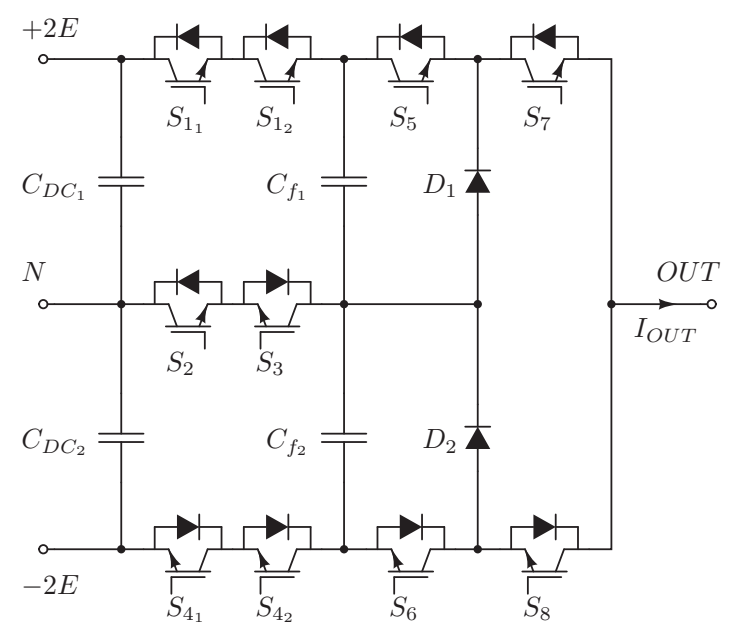

Fig. 3. Five-level stacked multicell inverter.

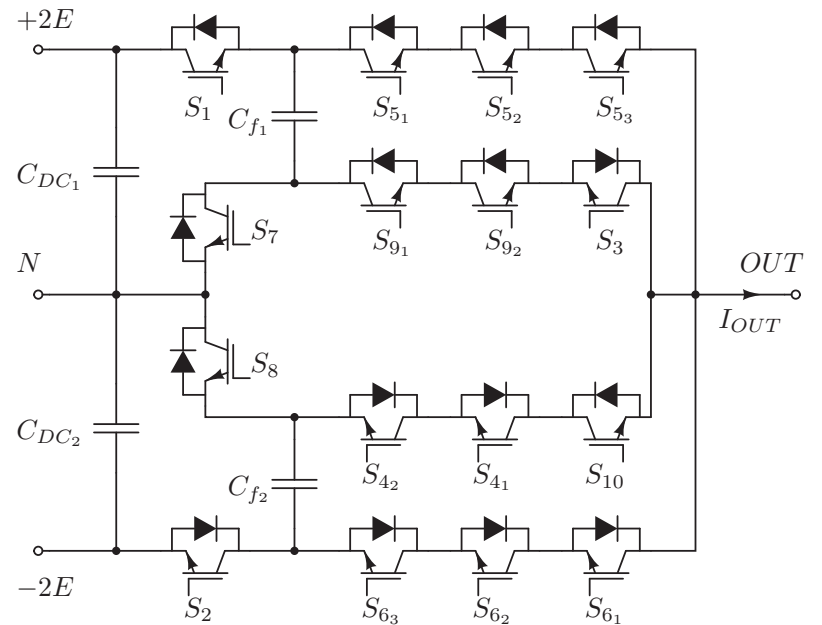

Fig. 4. Proposed five-level inverter topology: EDA5

$C_{D C_{1-2}}$. The schematic of EDA5 is presented in Fig. 4. Each switch in the converter is rated at $\mathrm{E}$, one-fourth of the total DC link voltage $4 E$. The charge state of floating capacitors $C_{f_{1-2}}$ is controlled by utilizing redundant states in order to keep capacitor voltages at $E$ for five-level voltage waveform (2E, $E, 0,-E$ and $-2 E)$ between output of the converter $(O U T)$ and neutral point $(N)$ of input DC-link capacitors $C_{D C_{1-2}}$.

\section{A. Switching States}

The switching states of the converter based on unity power factor operation are presented in Table I. Series connected switches such as $S_{X_{1}}$ and $S_{X_{2}}$ are switched on and off simultaneously, and therefore are represented as a single switch $S_{X}$ in the switching state table. Single state is available for $+2 E$ and $-2 E$ output voltage levels while two states are available for $+E$ and $-E$ output voltage levels and three states are available for zero output state. The two switching states for $+E$ and $-E$ levels are achieved by introducing floating capacitors to the path of output current $I_{O U T}$. Depending on the polarity of output current and voltage, the floating capacitors are charged or discharged. In Table I, the switching states $E_{C}$ and $E_{D}$ define the charging and discharging states respectively for floating capacitors at unity power factor operation and inverter mode. For zero output voltage, three possible paths can be used: 1) upper path $0_{P}$ formed by $S_{3}, S_{7}$ and $S_{9}, 2$ ) lower path $0_{N}$ formed by $S_{4}, S_{8}$ and $\left.S_{10}, 3\right)$ parallel path $0_{X}$ formed by simultaneous conduction of upper path $0_{P}$ and lower path $0_{N}$. The main benefit parallel zero state path $0_{X}$ is the reduction of conduction losses in the power cell during low modulation indexes or higher DC link voltages, where zero state conduction is dominant.

The current paths for four different switching states during positive half of output voltage for inverter mode are presented in Fig. 5. It can be seen from Figs. 4 and 5 that four devices are in conduction during all switching states except zero state $0_{X}$ where the output current is divided into two zero state branches. Charge or discharge state can be selected during $+E$ 
TABLE I

SWITCHING STATES

\begin{tabular}{c|cccccccccc} 
State & $S_{1}$ & $S_{2}$ & $S_{3}$ & $S_{4}$ & $S_{5}$ & $S_{6}$ & $S_{7}$ & $S_{8}$ & $S_{9}$ & $S_{10}$ \\
\hline \hline$+2 E$ & 1 & 0 & 0 & 0 & 1 & 0 & 0 & 0 & 0 & 0 \\
$+E_{C}$ & 1 & 0 & 1 & 0 & 0 & 0 & 0 & 0 & 1 & 0 \\
$+E_{D}$ & 0 & 0 & 0 & 0 & 1 & 0 & 1 & 0 & 0 & 0 \\
$0_{P}$ & 0 & 0 & 1 & 0 & 0 & 0 & 1 & 0 & 1 & 0 \\
$0_{N}$ & 0 & 0 & 0 & 1 & 0 & 0 & 0 & 1 & 0 & 1 \\
$0_{X}$ & 0 & 0 & 1 & 1 & 0 & 0 & 1 & 1 & 1 & 1 \\
$-E_{D}$ & 0 & 0 & 0 & 0 & 0 & 1 & 0 & 1 & 0 & 0 \\
$-E_{C}$ & 0 & 1 & 0 & 1 & 0 & 0 & 0 & 0 & 0 & 1 \\
$-2 E$ & 0 & 1 & 0 & 0 & 0 & 1 & 0 & 0 & 0 & 0
\end{tabular}

and $-E$ states in order to fix the floating capacitor voltage to the half of DC link capacitor voltage. For example, during unity power factor operation for inverter mode, at $+E_{C}$ state, switches $S_{1}, S_{3}$ and $S_{9}$ are turned-on in order to apply $+E$ state to the output by subtracting floating capacitor voltage $E$ from DC link capacitor voltage $+2 E$ while charging the floating capacitor. During $+E_{D}$ state, the voltage across floating capacitor is applied to the output of the converter by turning-on $S_{5}$ and $S_{7}$ switches. The "charging" or "discharging" status of a switching state can be defined by polarity of output voltage and direction of output current.

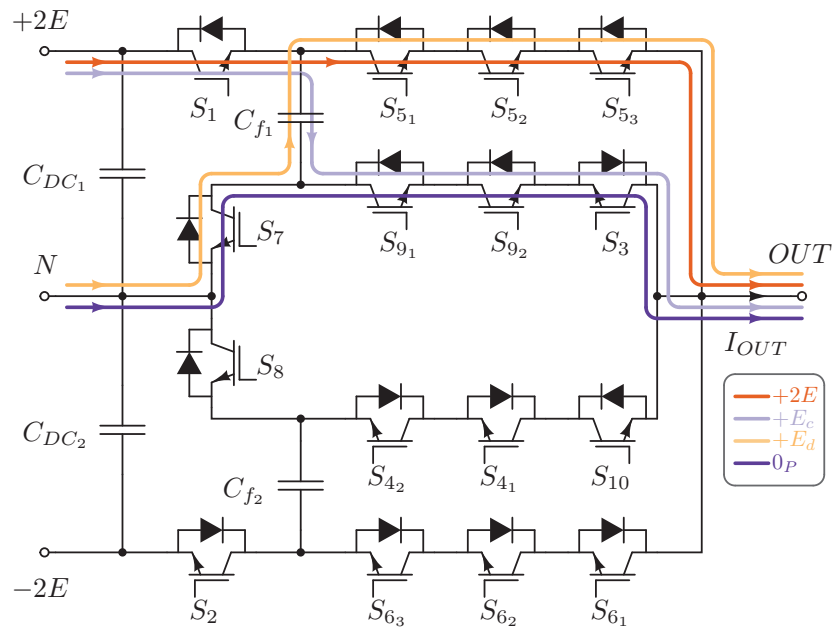

Fig. 5. Current paths for $+2 E,+E_{C},+E_{D}$ and $0_{P}$ states during positive half of output voltage.

\section{B. Commutation Scheme}

The commutation procedure between switching states, which are presented in Table I, has to be determined for transition of continuous output current from one state to another. The possible commutation schemes for the positive half of the output voltage for positive and negative output current are presented in Fig. 6. The blue and red curves for $V_{\text {OUT }}$ represents output voltage with positive and negative output currents respectively. Due to the nature of the topology, suitable commutations can be realised between $+2 E$ and $+E_{C-D}$ or $+E_{C-D}$ and $0_{P}$ states. The commutation between $+E_{C}$ and $+E_{D}$ is not possible without clamping the output to another voltage state. In the first commutation scenario from $+2 E$ to $+E_{C}$ in Fig. 6 (a), $S 9$ switch is turned-on first, and after the dead-time period $t_{d t}, S_{5}$ is switched-off and finally $S_{3}$ switch is turned-on. Depending on the direction of output current, the output voltage changes from $+2 E$ to $+E_{C}$ state after $t_{d t}$ or $2 t_{d t}$. Commutation schemes in Fig. 6 (b), (c) and (d) have similar structure with Fig. 6 (a), and all of the schemes can be realised by applying logic gates to PWM signals coming from the controller.

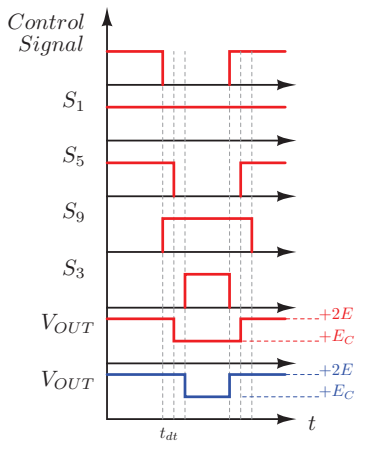

(a) $+2 E \Leftrightarrow+E_{c}$

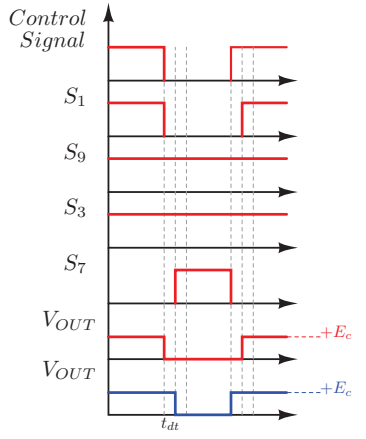

(c) $+E_{c} \Leftrightarrow 0_{P}$

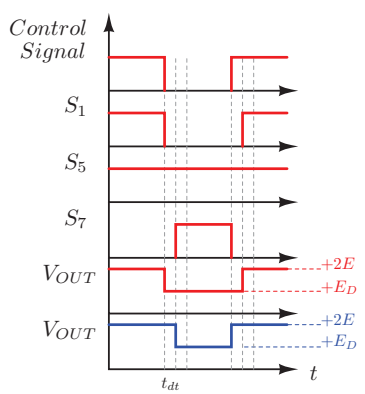

(b) $+2 E \Leftrightarrow+E_{d}$

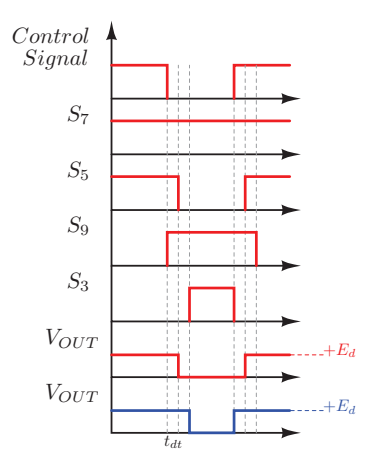

(d) $+E_{d} \Leftrightarrow 0_{P}$

Fig. 6. Commutation schemes for the positive half of the output voltage.

\section{Simulation Results}

The proposed topology is simulated in PLECS at inverter mode for evaluation of functionality and efficiency comparison with 5L-ANPC topology. The simulation conditions and converter parameters are presented in Table II. Medium voltage drive systems have been considered as the case study for the evaluation of the topology. Therefore commercial $1.7 \mathrm{kV}$, 800 A IGBT has been used in order to achieve $4.8 \mathrm{kV} \mathrm{DC}$ link voltage with 1.06 MVA output power [13]. Switching and conduction losses of switches at various operating conditions are calculated based on datasheet parameters at 125 ${ }^{\circ} \mathrm{C}$ junction temperature. Switching frequency is fixed to 2.5 $\mathrm{kHz}$ and current source is used in order to mimic continuous load current. The output voltage and current waveforms at $750 \mathrm{~kW}$ output power with 0.707 power factor are presented in Fig. 7. Modulation index is set to 0.9. It is proven that the converter can achieve five-level output waveform successfully by controlling floating capacitor voltages. 
TABLE II

Simulation AND CONVERTER PARAMETERS

\begin{tabular}{ccc}
\hline \hline Parameter & Symbol & Value \\
\hline Input Voltage & $V_{D C}$ & $4.8 \mathrm{kV}$ \\
Output Power & $P_{O U T}$ & $750 \mathrm{~kW}$ \\
Output Power Factor & $p f$ & 0.707 \\
Output Voltage & $V_{O U T}$ & $1.5 \mathrm{kV}$ \\
Switching Frequency & $f_{s w}$ & $2.5 \mathrm{kHz}$ \\
Switching Device & $S_{1-10}$ & $1.7 \mathrm{kV}, 800 \mathrm{~A} \mathrm{IGBT}$ \\
Junction Temperature & $T_{j}$ & $125^{\circ} \mathrm{C}$ \\
Total Floating Capacitance & $C_{f}$ & $10 \mathrm{mF}$ \\
\hline \hline
\end{tabular}

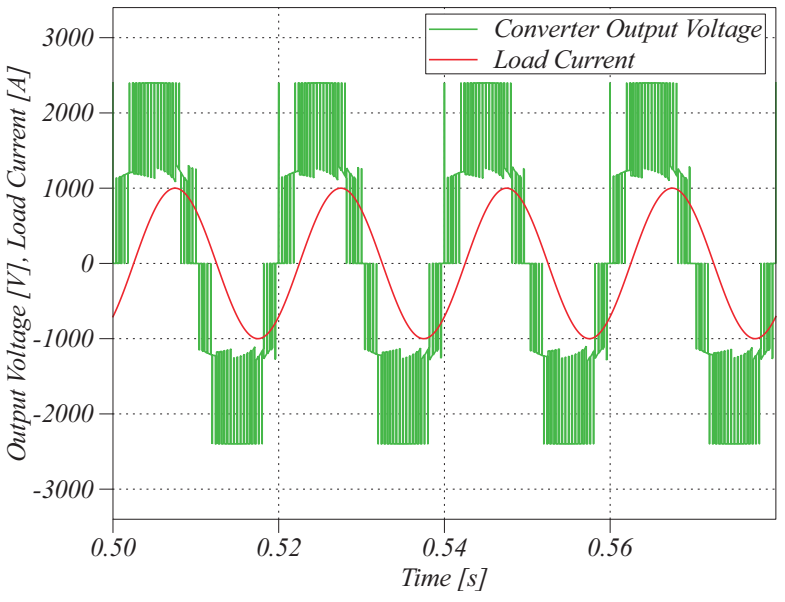

Fig. 7. Output voltage and current waveforms

Under same operating conditions, floating capacitor voltages for $C_{f_{1}}$ and $C_{f_{2}}$ capacitors are presented in Fig. 4. The floating capacitor voltages are controlled by individual hysteresis controllers for each capacitor where main DC link and floating capacitor voltages are measured and compared. The upper and lower band of hysteresis control are set as $26.25 \%$ and $23.75 \%$ of total DC link voltage respectively in order to provide $10 \%$ control margin. Floating capacitor voltages with respect to hysteresis band limits are presented in Fig. 8. It can be seen that the capacitor voltages are exceeding hysteresis limits at certain time of operation. The reason for that is the hysteresis controller is forcing the output control signal, which determines charge or discharge state for each capacitor, to be changed during $2 E, 0$ or opposite half of output signal with respect to each floating capacitor. As it is mentioned in commutation scheme section, the commutation of output current cannot happen between charging and discharging states and this approach prevents commutation between these two $E$ states. The state of charge of each floating capacitor is dependent on load current and switching frequency. Therefore, the control of floating capacitor voltage with the hysteresis controller can be improved by increasing switching and increase of capacitance for same load conditions.

In order to evaluate efficiency performance of proposed topology, 5L-ANPC is simulated under same operating conditions in Table II. Two operation scenarios for the converters are considered: 1) voltage source operation where modulation index is fixed and output current is varied, 2) current source
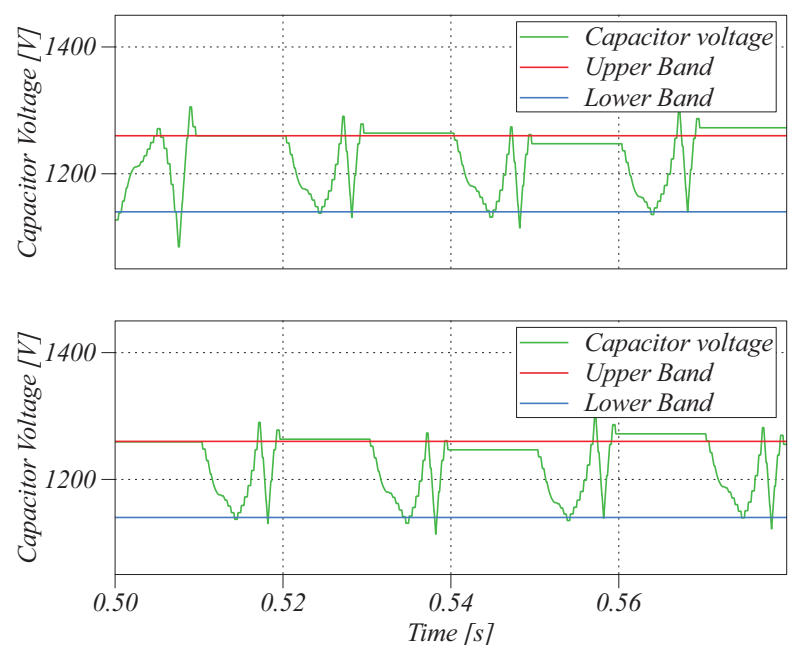

Fig. 8. $C_{f_{1}}$ and $C_{f_{2}}$ floating capacitor voltages.

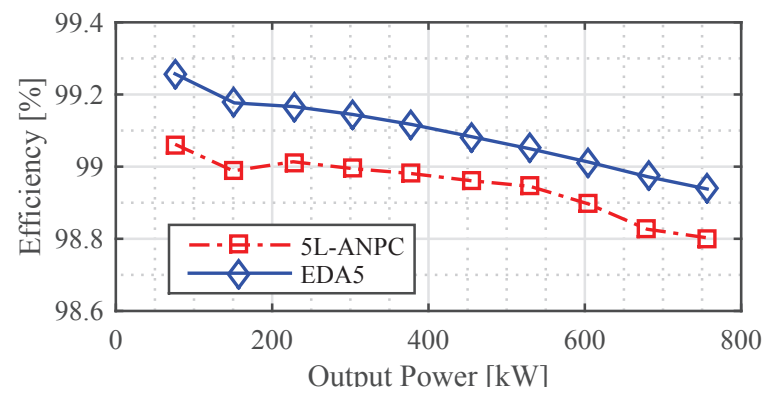

Fig. 9. Efficiency comparison with voltage source operation.

operation where output current is fixed and modulation index is varied. The efficiency results of single phase power cells for voltage source and current source operation are presented in Figs. 9 and 10 respectively. The results in Fig. 9 for voltage source operation show that proposed topology has approximately $0.2 \%$ higher efficiency under wide load range due to reduced conduction losses at zero voltage states. As presented in Fig. 10, during current source operation, the performance gap between proposed topology and 5L-ANPC is increased at light load conditions due to reduced conduction and switching losses at lower modulation index.

Switching and conduction losses for both operation modes have been analysed and presented in Figs. 11 and 12 for voltage source and current source operation respectively. With

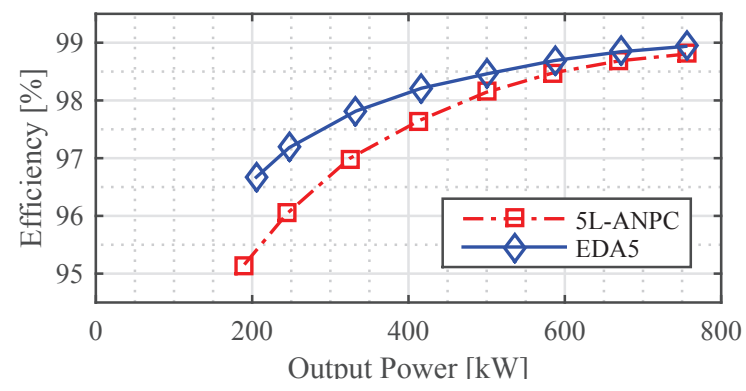

Fig. 10. Efficiency comparison with current source operation. 


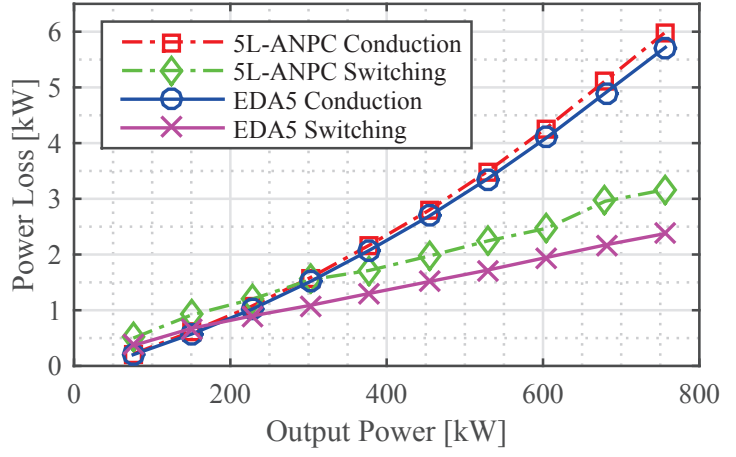

Fig. 11. Switching and conduction loss comparison with voltage source operation.

voltage source mode, the switching and conduction losses increase linearly and exponentially with respect to output power for both topologies. Although the conduction losses are similar, proposed topology has better switching performance in comparison to 5L-ANPC. The difference between switching losses is the reason for the efficiency difference between two topologies shown in Fig. 9. In current source mode, proposed topology has a significant advantage over 5L-ANPC under light load conditions due to reduced conduction and switching losses. This shows that proposed topology can operate with higher efficiency at higher DC link voltage and lower modulation index conditions.

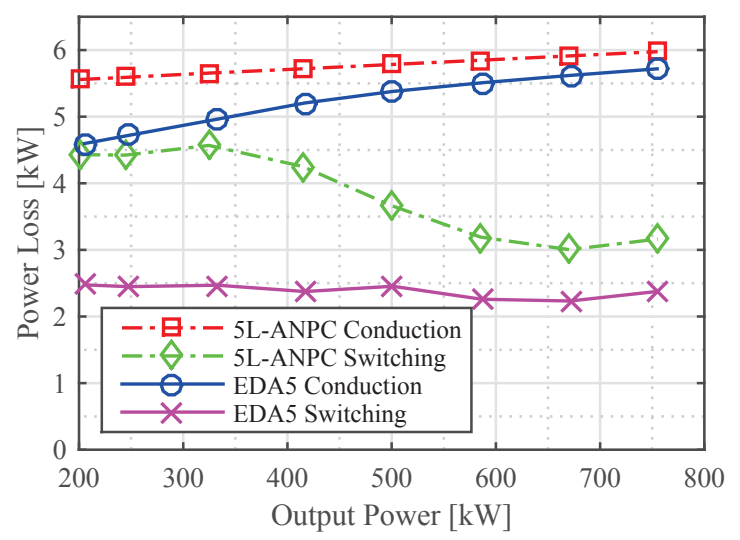

Fig. 12. Switching and conduction loss comparison with current source operation.

\section{EXPERIMENTAL RESULTS}

Experimental validation of the proposed hybrid inverter topology is completed by a $12 \mathrm{~kW}$ single phase prototype. The prototype test parameters are presented in Table III and photo of the prototype can be seen in Fig. 13. The system can be extended to three phase by stacking single phase building blocks. Single phase building block consist of DC link film capacitors, floating capacitors, DC link and floating capacitor voltage sensors, gate drivers, switches and turn-off snubbers. DC link voltage sensors are used to control the
TABLE III

PROTOTYPE PARAMETERS

\begin{tabular}{ccc}
\hline \hline Parameter & Symbol & Value \\
\hline Input Voltage & $V_{D C}$ & $1 \mathrm{kV}$ \\
Output Power & $P_{O U T}$ & $12 \mathrm{~kW}$ \\
Switching Frequency & $f_{s w}$ & $10 \mathrm{kHz}$ \\
Switching Device & $S_{1-10}$ & $600 \mathrm{~V}, 75 \mathrm{~A} \mathrm{IGBT}$ \\
Output Filter Inductor & $L_{f}$ & $1.5 \mathrm{mH}$ \\
\hline
\end{tabular}

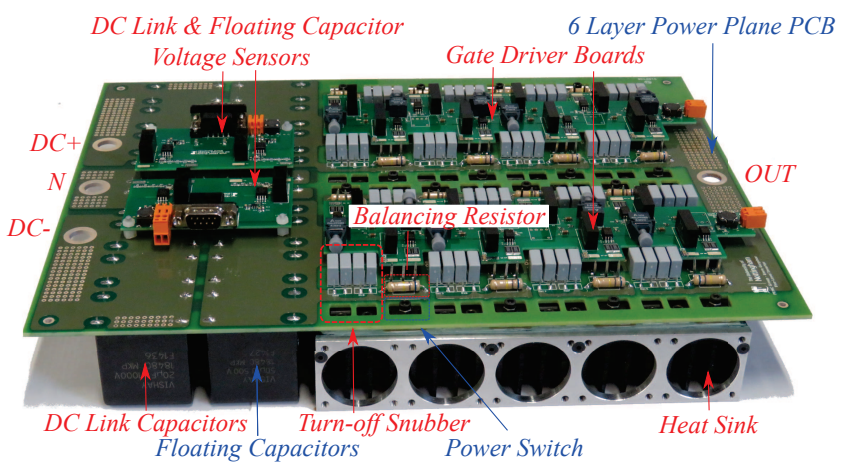

Fig. 13. Single phase $12 \mathrm{~kW}$ prototype.

floating capacitor voltage by hysteresis control implemented in DSP+FPGA control platform. Discrete IGBTs with antiparallel diodes are implemented with RCD turn-off snubbers in order to achieve dynamic and static voltage sharing between series connected IGBTs presented in Fig. 4. Power plane is formed by 6-layer PCB with $140 \mu \mathrm{m}$ copper on each layer for minimum parasitic inductance between commutating switches and minimum conduction losses.

The inverter output voltage and current waveforms at $2 \mathrm{~kW}$ and $12 \mathrm{~kW}$ output power conditions are presented in Figs. 14 and 15 respectively. The experimental results show that proposed topology successfully operates with an inductive load up to $12 \mathrm{~kW}$ output power. At $12 \mathrm{~kW}$ output power, it can be seen that output current is distorted due to the voltage variation at $\mathrm{E}$ and $-\mathrm{E}$ level $(250 \mathrm{~V},-250 \mathrm{~V})$ due to voltage variation across floating capacitors $C_{f_{1}}$ and $C_{f_{2}}$. The floating capacitor voltage with respect to DC link capacitor voltage is presented in Figs. 16a and $16 \mathrm{~b}$ at $2 \mathrm{~kW}$ and $12 \mathrm{~kW}$ output power conditions. Although the average voltage of floating capacitor is fixed to half of DC link capacitor voltage $250 \mathrm{~V}$ for both load conditions, the peak-to-peak voltage variation across floating capacitor is increased from $30 \mathrm{~V}$ to $180 \mathrm{~V}$ with the increase of output current. The reason for the large variation at high output power is the sensor accuracy and limitations of control board. Due to control board limitations, the update rate for floating capacitor control is limited to $1 \mathrm{kHz}$ and the effect of low update frequency makes voltage fluctuation more severe at higher output current conditions. This can be solved by improving accuracy of the sensors and also implementing the hysteresis control in the FPGA rather than DSP.

Finally, efficiency figures of the prototype power cell and total converter at $1 \mathrm{kV}$ DC link voltage and 0.72 modulation 


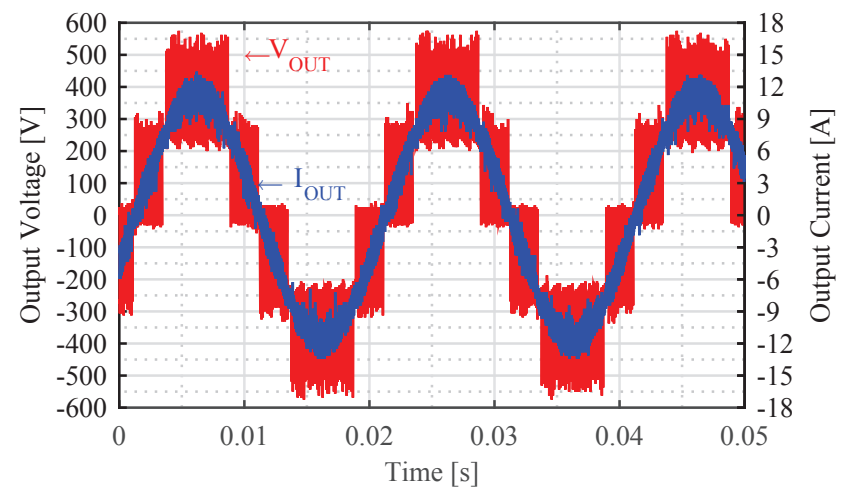

Fig. 14. Experimental output voltage and current waveforms at $2 \mathrm{~kW}$ output power.

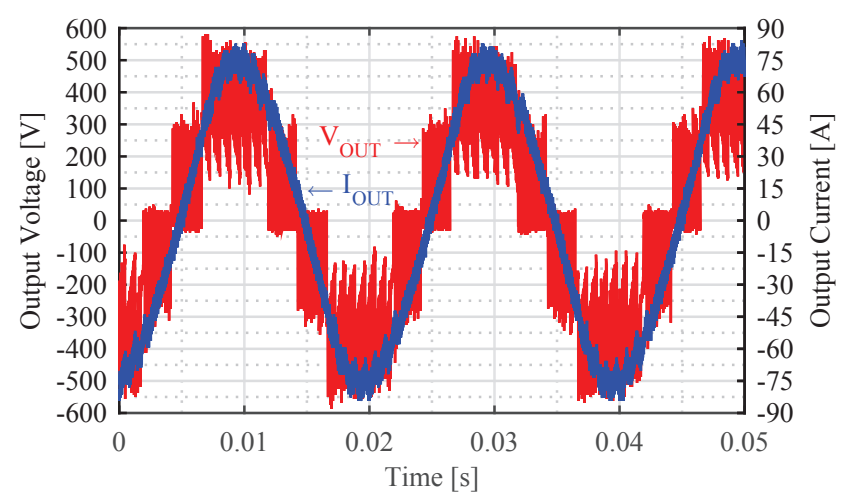

Fig. 15. Experimental output voltage and current waveforms at $12 \mathrm{~kW}$ output power.

index are presented in Fig. 17. The power cell efficiency curve includes DC link capacitor and power switch losses; and total efficiency curve includes power cell losses and output inductor losses. It can be seen that the prototype power cell can achieve $96 \%$ peak efficiency with Si IGBTs. The main objective of the prototype is demonstration of the functionality of EDA5 topology at high voltage and high power conditions. The efficiency of the prototype can be further improved by increasing the current capability of Si IGBT gate drivers and optimising RCD snubbers to minimise switching loss.

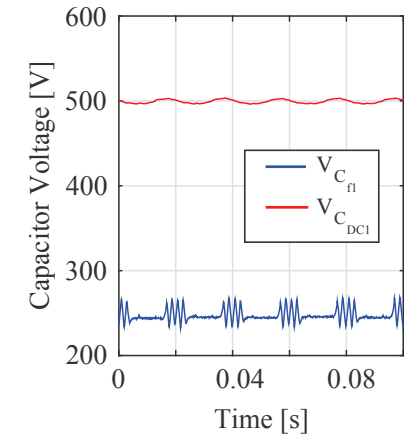

(a)

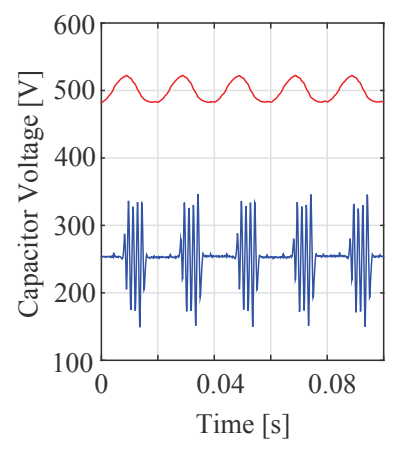

(b)
Fig. 16. DC link and floating capacitor voltage at (a) $2 \mathrm{~kW}$ and (b) $14 \mathrm{~kW}$ output power.

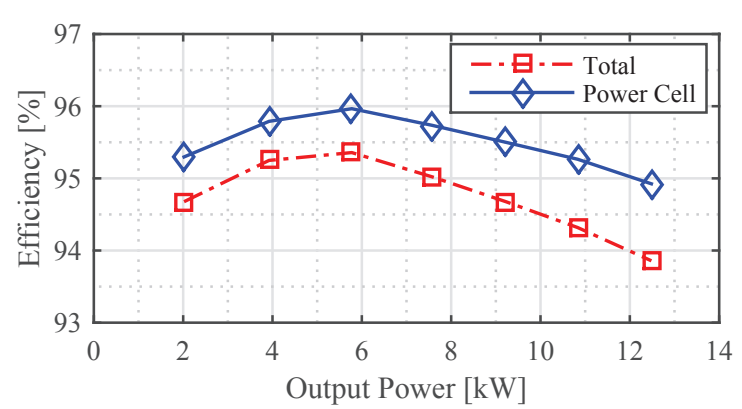

Fig. 17. Efficiency of the prototype at $1 \mathrm{kV}$ DC link voltage and 0.72 modulation index.

\section{CONCLUSION}

In this paper, a novel five-level hybrid inverter topology for renewable energy systems and high power applications has been presented including description switching states and commutation scheme. The proposed topology is compared with state-of-the-art hybrid multilevel topologies in simulation. Simulation results show that EDA5 provides higher efficiency in comparison to 5L-ANPC, especially at lighter load conditions. The functionality of the topology has been verified experimentally with a $12 \mathrm{~kW}$ single phase prototype.

\section{REFERENCES}

[1] J. Rodriguez, J.-S. Lai, and F. Z. Peng, "Multilevel inverters: a survey of topologies, controls, and applications," IEEE Trans. Ind. Electron., vol. 49, no. 4, pp. 724-738, Aug 2002.

[2] J.-S. Lai and F. Z. Peng, "Multilevel converters-a new breed of power converters," IEEE Trans. Ind. App., vol. 32, no. 3, pp. 509-517, May 1996.

[3] A. Nabae, I. Takahashi, and H. Akagi, "A new neutral-point-clamped pwm inverter," IEEE Trans. Ind. App., vol. IA-17, no. 5, pp. 518-523, Sept 1981.

[4] M. D. Manjrekar, P. K. Steimer, and T. A. Lipo, "Hybrid multilevel power conversion system: a competitive solution for high-power applications," IEEE Trans. Ind. App., vol. 36, no. 3, pp. 834-841, May 2000.

[5] T. Bruckner, S. Bernet, and H. Guldner, "The active npc converter and its loss-balancing control," IEEE Trans. Ind. Electron., vol. 52, no. 3, pp. 855-868, June 2005.

[6] P. Barbosa, P. Steimer, J. Steinke, M. Winkelnkemper, and N. Celanovic, "Active-neutral-point-clamped (anpc) multilevel converter technology," in Proc. of EPE, Sept 2005, pp. 10 pp.-P.10.

[7] F. Kieferndorf, M. Basler, L. A. Serpa, J. H. Fabian, A. Coccia, and G. A. Scheuer, "A new medium voltage drive system based on anpc-51 technology," in Proc. of ICIT, March 2010, pp. 643-649.

[8] P. Barbosa, P. Steimer, and T. Chaudhuri, "Converter circuit for switching a large number of switching voltage levels," Sep. 17 2009, US Patent App. 12/421,660. [Online]. Available: http://www.google.ch/patents/US20090231896

[9] M. Yatsu and K. Yoda, "Five-level converter," Apr. 6 2011, EP Patent App. EP20,100,177,221. [Online]. Available: http://google.com/patents/EP2306629A2?cl=fi

[10] S. Dargahi, E. Babaei, S. Eskandari, V. Dargahi, and M. Sabahi, "Flyingcapacitor stacked multicell multilevel voltage source inverters: analysis and modelling," IET Power Electron., vol. 7, no. 12, pp. 2969-2987, 2014.

[11] G. Gateau, T. A. Meynard, and H. Foch, "Stacked multicell converter (smc): properties and design," in Proc. of PESC, vol. 3, 2001, pp. 15831588 vol. 3.

[12] E. Gurpinar, D. De, and A. Castellazzi, "Power converter," Patent Application GB 1520961.2, 11 27, 2015.

[13] 5SND 0800M170100 Hi PAK IGBT Module, ABB Switzerland Ltd, Semiconductors, Apr. 2014, doc. No. 5SYA1589-01. 